\title{
A INSUFICIÊNCIA NA RAZÃO
}

Eduardo Luft*

SÍNTESE - Este trabalho trata da necessidade de repensar a idéia de sistema na Filosofia, levando em consideração as críticas feitas após o Idealismo Alemão contra uma tal tentativa. Se a razão pretende se elevar a um sistema, ela necessariamente deve incluir dentro de si a sua própria insuficiência. A razäo deixaria de se apresentar, então, com a rigidez dos sistemas construídos na modernidade, alguns deles fortemente baseados no paradigma da Matemática.

\begin{abstract}
This paper is about the necessity of rethinking the idea of system in Philosophy, taking in account the critics made after German Idealism against this try. If reason intends to elevate itself into a system, it must necessarily include in itself its own insufficiency. Reason would not, then, present itself anymore with the regidity of systems constructed in modernity, some of them strongly based on the paradigm of Mathematics.
\end{abstract}

\begin{abstract}
"Só um (ser) vivo (Lebendiges) sente insuficiência (Mangel); pois apenas ele é, na natureza, o conceito que é a unidade de si mesmo e do seu contrário determinado. Onde existe um limite, este é uma negação apenas para um terceiro, para uma comparação externa. Mas há insuficiência na medida em que em um existe também algo que o ultrapassa, a contradição que enquanto tal lhe é imanente e nele está posta. Algo assim (um Lebendiges), que é capaz de ter em si a contradição de si mesmo e de suportá-la, é o sujeito; isto constitui a sua infinidade". ${ }^{1}$
\end{abstract}

Talvez a característica mais surpreendente da crítica realizada por Cirne-Lima ao sistema de $\mathrm{Hegel}^{2}$ esteja justamente na sua insistência em reconstruir um projeto de sistema. Até que ponto, diante das perspectivas atuais da filosofia, ainda é possível levantar uma pretensão sistemática, e em que medida esta idéia pode se tornar realmente frutifera?

A longa tradição crítica pós-idealismo alemão procurou minar justamente toda e qualquer pretensão da razão em se constituir como um sistema do saber. ${ }^{3}$ Esta visão totalizante, oniabragente da filosofia - tendo o sistema de Hegel como seu

Pontifícia Universidade Católica do Rio Grande do Sul, PUCRS

1 HEGEL, Enzyklopädie der philosophischen Wissenschaften, \& 359, p. 469.

2 CIRNE-LIMA, Sobre a Contradição. p. 67ss.

3 Segundo BORNHEIM: "Seja pelo voluntarismo, ou pela vivência irracional, ou pelo inconsciente, ou pela história voltada ao particular, ou pela atenção ao homem enquanto singular concreto, desde a fé kierkegaardiana até o corps propre de Merleau-Ponty, tudo parece confirmar, ao menos a nível filosófico, a decadência terminante do próprio conceito de sistema" ("Presença da Razão", in: HÜHNE (org.), Razões, p. 10). 
representante mais emblemático - deveria ser banida, para preservar a liberdade do homem na história, a singularidade do agir humano. ${ }^{4}$ É deste horizonte que surgirá a ênfase na fragilidade da razão humana, na parcialidade e na fragmentação de toda e qualquer compreensão racional do mundo.

Este processo ganhará em Nietzsche uma radicalidade pouco vista, chegando a abarcar uma crítica não só à racionalidade em sua formação especificamente moderna, mas a toda a tradição metafísica. É a idéia fundamental da metafísica de elevar a razão a um sistema que deve ser banida. O problema é que a idéia de sistema da razão está por demais arraigada dentro da própria concepção do fazer filosófico: daí a necessidade de estender a crítica, como faz Nietzsche, aos mais recônditos horizontes da metafísica tradicional. O conceito de sistema vem originariamente do grego sýstêma. Este conceito é formado pela junção do advérbio sýn, significando "todos juntos", "juntamente", com o verbo hístêmi, que significa "colocar". E, desde muito cedo, a idéia de sistema esteve vinculada à concepção de uma razão universal. Assim, a idéia de "colocar em conjunto", ou de formar um sistema, fundamentando-o em um princípio racional universal, é algo inerente à própria concepção de filosofia desde Platão: cabe à filosofia dar uma visão de conjunto dos diversos campos do saber humano, revelando o sentido do mundo: só assim a verdade é realmente o desvelamento (alétheia) do lógos em toda a sua universalidade, nas suas diversas manifestações.

Neste sentido, a amplitude de uma crítica como a de Nietzsche revela também a sua fraqueza: é inevitável que uma crítica assim constituída venha a se colocar externamente em relação ao(s) sistema(s) criticado(s). A argumentação assim estabelecida pode servir como uma fascinante denúncia, mas ela mesma não pode lançar frutos sobre o terreno minado. ${ }^{5}$

Esta perspectiva crítica em relação à idéia de sistema segue até a filosofia atual. A restrição de horizontes da atividade filosófica gerou dois campos de estudo que hoje em dia ganham preponderância: a análise lógica da linguagem (onde a filosofia pode ainda gozar de uma certa rigidez metodológica, embora se recuse como totalidade do saber) e os trabalhos que enfatizam a fragilidade, o caráter fragmentário da razão. Nestes dois campos a racionalidade encontra fora de si um terreno obscuro ao qual não se deve aventurar, e o qual constitui o seu limite. Enquanto a razão ficar confinada a estes limites será impossivel pretender elevá-la a um sistema totalizante. Este lado obscuro para a razão pode aparecer sob diversas formas, desde a finitude radical da existência humana, o ser para a morte (marca fundamental do Dasein em Heidegger), até o indizivel ${ }^{6}$ do além dos limites da linguagem, no Tractatus de Wittgenstein.

Dentro de todo este panorama traçado não deveríamos estar plenamente convencidos da ineficácia - para não dizer do caráter absurdo - da elaboração de qualquer projeto de sistema? Acredito, no entanto, que deveríamos encontrar dentro

4 Este é um dos grandes temas da filosofia de Kierkegaard, e o motivo central de suas críticas a Hegel: é preciso opor de um modo radical sistema e existência.

5 Sobre a crítica extema, cf. LUFT, Para Uma Crítica Intema ao Sistema de Hegel, cap. I e II.

6 Esta é a famosa frase que encerra o Tractatus: "Acerca daquilo de que se não pode falar, tem que se ficar em silêncio" (6.54, p. 142). 
desta tradição crítica - mesmo que isto em alguns casos não esteja colocado explicitamente - muito mais a idéia da rejeição de uma forma específica de sistema, baseada em uma também específica concepção de racionalidade, do que (embora em certos autores exatamente esta perspectiva esteja presente) de toda e qualquer concepção de sistema.

Assim podem ser entendidas algumas das críticas realizadas ao sistema de Hegel. Podemos observar, por exemplo, que as críticas de Schelling - que tiveram posteriormente desdobramentos mais radicais em outros autores - visam atacar a concepção específica de sistema elaborada por Hegel, em sua tendência a desconsiderar o âmbito de atuação do sujeito finito. Para Schelling, a pretensão sistemática de Hegel desconsiderava a contingência das visões de mundo do sujeito finito. ${ }^{7}$ Schelling, neste ponto específico, não estava se voltando contra toda e qualquer idéia de sistema.

Isto é emblemático por um motivo bastante simples: aquilo que o sistema de Hegel traz consigo, e que deve ser rejeitado, é algo que não diz respeito só a ele, mas que se constitui provavelmente na grande aporia do projeto moderno de racionalidade: o conflito entre uma concepção racional sistemática (e, portanto, totalizante) e a liberdade humana. Mas a origem deste problema não está em Hegel -e pode-se dizer que, em certo aspecto, a dialética de Hegel representa uma tentativa de superação deste conflito entre razão e liberdade - e sim na idéia de razão fundada no conhecimento objetivo da natureza, tendo como paradigma o método construtivista da matemática, o que é típico no racionalismo inaugurado por Descartes.

A falência deste projeto de racionalidade nos levou a uma postura de descrença radical. ${ }^{8}$ Segundo Manfredo A. de Oliveira:

"A palavra absurdo, em nossa situação epocal, aponta para uma suspeita de perda de sentido para a vida humana: a suspeita de que a pretensão originária que marca nosso processo civilizatório desde as suas origens a uma civilização da razão mostra-se hoje uma ilusão. [...] A racionalidade ter-se-ia tornado ćnica $[\ldots]^{1}{ }^{9}$

Uma das conseqüências diretas do desmoronamento deste projeto racional foi a ampla relativização da própria racionalidade, o que tem condenado a filosofia a um louvor do non-sense. Daí a exigência de Cirne-Lima: "É preciso, penso, atacar de frente o problema da contradição, e, tentando resolvê-lo, procurar restabelecer a unidade da razão; é preciso reconstruir o grande mosaico do sentido do mundo, de sua História e de nossas vidas, sob pena de tudo ficar para sempre sob o signo do absurdo, do non-sense". ${ }^{10}$

7 SCHELLING afirma: "[...] a própria filosofia de Hegel mostra quantos lados desse mundo efetivo ele não apreendeu; não se deve excluir, pois, a contingência daquele prosseguimento, isto é, o contingente das visões do mundo individuais mais estreitas ou mais amplas do sujeito filosofante" (Ausgewählte Schriften, v. 4, p. 548).

8 BORDIN afirma: "A modernidade teve, sem dúvida, uma relação privilegiada com a mudança, sobretudo no horizonte do iluminismo e do idealismo. Mas, hoje em dia, parece que uma ruptura interveio abruptamente e tudo parece acontecer sob a forma do trágico" ("Razão Pós-moderna", in: HÜHNE (org.), Razões, p. 160).

9 OLIVEIRA, Manfredo A. Ética e Racionalidade Moderna, p. 68.

10 CIRNE-LIMA, Sobre a Contradição, p. 10. 
Mas, afinal, o que nos levou a demolir este "mosaico do sentido do mundo"? $\mathrm{Ou}$, dito de outra forma, que tipo de "sentido do mundo" a filosofia moderna ergueu, e que terminou se revelando como algo paradoxal?

\section{Sistema e racionalidade moderna}

A emergência da subjetividade na era moderna esteve marcada indelevelmente pela influência da visão de mundo levantada pelo avanço radical das ciências naturais. É Descartes que elevará o projeto de objetivação do mundo a uma elaboração sistemática consistente. Demonstrada a indubitabilidade do cogito cartesiano, a razão tem como seu paradigma último o método construtivista da matemática, e como meta a dominação da natureza através da ciência. O universo é este "livro aberto", e "escrito em linguagem matemática", segundo Galileu. A natureza não é mais - como para o realismo ingênuo - imediatamente apreendida pelo espírito, mas passa a ser concebida como "coisa extensa", ou em sua estrutura meramente quantitativa, passivel de ser dominada pelo espírito humano até o seu último pormenor.

Esta concepção sobre a natureza e o kósmos é algo que diferencia fortemente o pensamento moderno das concepções grega e medieval, embora também exista, naturalmente, uma linha de continuidade neste projeto de racionalização do mundo. ${ }^{11}$

Para os gregos, a natureza se revelava como phýsis, um princípio interno que dá ordem e sentido às coisas, e que, segundo Heráclito, "tende a ocultar-se" ${ }^{12} \mathrm{O}$ desvelamento ou desocultamento (alétheia - verdade) da phýsis revelava ao homem um todo pleno de sentido, e do qual ele mesmo fazia parte. O sentido do homem se revelaria a partir da compreensão do sentido prejacente ao próprio ser, a partir do entendimento do lugar do homem no kósmos.

A filosofia moderna nos apresentará um sentido radicalmente inverso: apenas o cogito em Descartes é verdadeiramente indubitável, e é a partir de sua indubitabilidade que poderemos construir uma concepção plausível de natureza, marcada agora pela racionalidade lógico-matemática. O homem já não se encontra dentro do sentido maior do próprio kósmos, mas se contrapõe à natureza como seu dominador, e a objetifica. O sujeito empresta o sentido possivel à natureza.

Mas esta mesma pretensão desmesurada do homem se revelará como sua armadilha. A constituição desta racionalidade objetificadora como núcleo de uma concepção sistemática passa a ver a totalidade do real como um objeto, e isto terminará por incluir, inevitavelmente, o próprio homem. A racionalidade lógico-mate-

11 Segundo HEIDEGGER: "A frase: a filosofia é grega em sua essência não diz outra coisa que: o Ocidente e a Europa, e somente eles, são, na marcha mais íntima de sua histónia, originariamente 'filosóficos'. Isto é atestado pelo surto e domínio das ciências. Pelo fato de elas brotarem da marcha mais íntima da história ocidental-européia, o que vale dizer do processo da filosofia, são elas capazes de marcar hoje, com seu cunho específico, a história da humanidade pelo orbe terrestre" (Que é Isto - a Filosofia?, in: Os Pensadores, p. 14-15).

12 MONDOLFO, Heráclito (frg. 123), p. 45. 
mática ocupa agora um lugar que não lhe cabe de fato, ${ }^{13}$ ou seja, ela pretende assumir o lugar central do sistema filosófico. É inevitável a futura incompreensão do homem moderno para os problemas verdadeiramente humanos, e a conseqüente desvalorização das ciências do espírito. O homem objetificado se desumaniza: um processo que tem seu ápice no trabalho alienado do operário nas fábricas, denunciado de modo tão contundente por Marx.

É dentro deste contexto que surge a pergunta pela liberdade do homem. Como é possível pensar um lugar específico onde esteja fundamentada a liberdade humana, a partir de uma compreensão de mundo que encontra lugar apenas para as leis necessárias da natureza e para o aspecto quantitativo da "coisa extensa"? A elevação da racionalidade moderna a uma concepção sistemática não poderia resultar senão na perda de lugar da criatividade e da liberdade do homem.

Daí a importância fundamental do pensamento de Kant, que vê uma única alternativa possível para conciliar a liberdade humana e as concepções da nova ciência da natureza: a distinção entre númeno e fenômeno. Somente assim está garantido o âmbito através do qual se dá a liberdade transcendental, fora do império do princípio da causalidade: a "vontade deve conceber-se como totalmente independente da lei natural dos fenômenos nas suas relações recíprocas, a saber, da lei da causalidade. Uma tal independência, porém, chama-se liberdade no sentido mais estrito, isto é, transcendental". ${ }^{14}$

Mas, logo que foi superada a dicotomia kantiana entre númeno e fenômeno, o problema ressurgiu com toda a força, agora sob outra forma. O grande projeto de Fichte é justamente realizar a Doutriną da Ciência, cuja meta prioritária é encontrar os princípios a partir dos quais seria permitido deduzir os axiomas de toda a ciência possível. A razão prática funda a teórica e traz a possibilidade do esgotamento de todo o saber possível: "[...] nosso sistema acrescenta uma parte prática, que funda e determina esta primeira (parte teórica), perfaz com isso a ciência inteira e esgota tudo o que é encontrado no espírito humano". ${ }^{15}$ Ora, como conciliar este esgotamento realizado pela razão e o espaço da liberdade humana? O único recurso para resolver este problema, Fichte 0 concebe através do caráter infinito da atividade do eu que, nunca encontrando término, deixa espaço suficiente para a realização da liberdade. Ou melhor, a liberdade é a atividade do eu, enquanto tem por objeto sua própria infinitude. ${ }^{16}$

13 É mérito de Kant ter denunciado o caráter dogmático de qualquer empreendimento que busque identificar o tipo de conhecimento matemático com o filosófico, marcando o estrito limite entre os dois: "Importa-nos muito saber, portanto, se o método para alcançar a certeza apodítica, que se chama matemático nesta última ciência, é idêntico àquele com que unicamente se procurava a mesma certeza na filosofia e neste caso devia chamar-se dogmático. [...] O conhecimento filosófico considera, pois, o particular apenas no geral, o conhecimento matemático, o geral no particular e mesmo no individual [...]" (Crítica da Razão Pura, B 741-2).

14 KANT, Crítica da Razão Prática, p. 40.

15 FICHTE, "A Doutrina da Ciência de 1794", in: Os Pensadores, 122-3.

16 Segundo HARTMANN: "Se o objeto de aspiração fosse finito e acessivel, a aspiração teria de eliminar-se nele e, portanto, ter-se-ia alcançado o estado de inércia. $\mathrm{O}$ homem moral não age, em regra, para alcançar qualquer coisa e desfrutar o alcançado [...]. O seu labor existe pelo próprio labor, o seu fim último é o etemamente inacessivel - a Idéia" (A Filosofia do Idealismo Alemão, p. 98). 
É dentro deste contexto que surge a filosofia de Hegel. Uma das intenções primordiais de Hegel permanece sendo conciliar a necessidade do sistema com a liberdade do homem. Até que ponto Hegel teria efetivamente conseguido realizar a sua pretendida unidade entre o sujeito livre de Kant e a substância de Espinosa? Esta é a pergunta fundamental, a que Cirne-Lima responde de modo negativo: "Hegel inclina-se - sobre isso não há a menor dúvida - para o necessitarismo, no qual a liberdade é apenas uma necessidade interiorizada, no qual uma Razão do Universo, que é totalmente impessoal - e não nós mesmos - determina o sentido da natureza e da História". ${ }^{17}$

Mas de que modo, efetivamente, é possível conciliar liberdade humana e projeto de sistema, ou livre-arbítrio individual e racionalidade totalizante? Não incorreríamos aqui em um erro evidente, tentando unir opostos irreconciliáveis? Uma resposta é óbvia: se mantivermos como núcleo do sistema uma racionalidade objetificadora e baseada no paradigma do método construtivista da matemática não encontraremos mais lugar para esta liberdade do sujeito finito, tão proclamada pela filosofia contemporânea. É justamente o encontro de um lugar para a liberdade do sujeito finito que Cirne-Lima considera como o diferencial básico de seu sistema em relação às ambigüidades do sistema hegeliano.

\section{Sistema e contradição por insuficiência}

Dificilmente poderemos compreender o projeto de Cirne-Lima se não considerarmos com certa atenção o projeto racional fundado pela dialética de Hegel. O curioso em todas as críticas que costumam ser feitas a Hegel é que dificilmente se percebe o quanto uma das características fundamentais da filosofia contemporânea - a ênfase na historicidade da razão - tem no filósofo alemão o seu precursor.

A razão ser histórica significa que seu processo de autodeterminação se dá através da resolução constante de suas insuficiências: o absoluto está desde sempre imerso na finitude. Em Hegel não é mais possivel pensar em um suposto eu absoluto cuja atividade, como ocorre no idealismo de Fichte, ${ }^{18}$ se realiza a partir da abstração das condições empíricas do conhecimento. Também não temos em Hegel a segurança e a indubitabilidade do cogito cartesiano. O lógos absoluto é em Hegel resultado de um processo doloroso - "a dor do Conceito" - de autodeterminação que não pode prescindir jamais de sua historicidade originária.

Neste sentido, não é difícil reconhecer o papel da contradição por insuficiên$\mathrm{cia}^{19}$ nos mais variados pontos do sistema hegeliano. Ao contrário do eu absoluto, nos deparamos, ao início da Fenomenologia do Espírito (a porta de acesso ao siste-

17 CIRNE-LIMA, Sobre a Contradição, p. 99.

18 De acordo com FICHTE: "[...] o pura e simplesmente posto e fundado em si mesmo é fundamento de um certo (pela Doutrina da Ciência inteira se verificará que de todo) agir do espírito humano; é, por conseguinte, seu caráter puro; o caráter puro da atividade em si, abstração feita de suas condições empíricas" (A Doutrina da Ciência de 1794, 96).

19 Sobre a distinção entre contradição por insuficiência, contradição implosiva (disruptiva) e contradição sintética, cf. LUFT, Para Uma Crítica Interna ao Sistema de Hegel, p. 82-3. 
ma hegeliano) com o âmbito da consciência de um indivíduo singular finito. ${ }^{20}$ Teremos inevitavelmente de percorrer a longa trajetória dos erros e acertos da consciência, através do percurso fenomenológico, até atingirmos o saber absoluto. Hegel afirma:

"Como o espírito que sabe o que ele é, ele não existe anteriormente, e não existe em parte alguma, senão depois de completado o trabalho de dominar sua figuração imperfeita, de obter para a sua consciência a figura de sua essência, e para desta maneira igualar a sua autoconsciência à sua consciência". 21

Ao mesmo tempo, é impossível compreender a Lógica de Hegel sem levar a sério a insuficiência que caracteriza o isolamento inicial de cada conceito - enquanto tese e antítese - e que nos obriga a ir além, obtendo uma síntese, que se torna também ela provisória, até chegarmos à idéia absoluta. Segundo McTaggart: "O ponto máximo do método dialético é que a percepção da contradição é a razão para abandonarmos a categoria que percebemos como contraditória". ${ }^{22}$ A contradição por insuficiência é a marca do negativo que permeia todo o sistema, de ponta a ponta, e que, quando não superada, resulta no surgimento da contradição disruptiva, ${ }^{23}$ ou do irracional (embora esta possibilidade esteja em suspenso no âmbito da própria Lógica). Este é o caso na dialética do senhor e do escravo e no capítulo sobre a liberdade absoluta e o terror, ambos na Fenomenologia.

Esta interiorização da insuficiência, ou do negativo, é que, se levada devidamente a sério, marcará a grande distância entre uma crítica da razão que inclua no bojo desta a sua própria insuficiência - ou seja, uma crítica realmente interna - e a outra crítica que só vê como possível considerar este outro da razão como algo totalmente estranho e externo a ela.'

Ora, a característica em comum das críticas à idéia de sistema apresentadas ao começo deste trabalho é justamente determinar o limite da racionalidade como algo efetivado externamente a ela mesma ${ }^{24}$ - como se fosse possível verdadeira-

20 Segundo expressão de MURE, La Filosofia de Hegel, p. 73.

21 HEGEL, Phänomenologie des Geistes, p. 583.

22 McTAGGART, A Commentary on Hegel's Logic, p. 116.

23 Este é o conceito que o autor passa agora a utilizar, em substituição a contradição implosiva (cf. LUFT, Para Uma Crítica Interna ao Sistema de Hegel, p. 82). A contradição disruptiva expressa melhor o que de fato ocorre com a emergência do irracional. O termo disruptivo provém do Latim: disrumptus (v. disrumpere: romper, quebrar). No Português esta palavra é uma variante de diruptivo: "que provoca ruptura, que arruina, destruidor". Trata-se, portanto, de uma ruptura (ou cisão) acompanhada de destruição. Em Inglês o termo é disruptive. O verbo disrupt significa exatamente, segundo o Websters: to break apart (quebrar em fragmentos, em pedaços); disruption significa: the fact or state of being disrupted (o fato ou estado do ser que se despedaçou). Disruptivo (em contradição disruptiva) revela, portanto, aquela quebra em fragmentos da unidade racional, a destruição do ser.

24 FERRY e RENAUT detectam também como críticas externas aquelas realizadas por Heidegger e por Adomo e Horkheimer - cada qual à sua maneira - contra a racionalidade moderna. Os autores denunciam o caráter problemático desta exterioridade radical em que se coloca a crítica através destes autores, lançando a idéia de uma crítica intema ao projeto moderno: "Para além das suas divergências, estes dois tipos de críticas têm no entanto em comum o projeto de uma desconstrução da modernidade que, em nome da tradição ou em nome da utopia, é, seja como for, sempre denunciada de um ponto de vista exterior a ela. Ousemos confessá-lo: é o estatuto e a legitimidade desta exterioridade radical que atualmente nos parece que se torna constantemente mais problemática - eis 
mente estabelecer um tal limite, sem instantaneamente superá-lo. Este outro, que permanece inabarcável para a razão, é um inimigo contra o qual é impossível combater, e passa a ser um aliado na negação da pretensão totalizante de qualquer filosofia.

Uma filosofia sistemática como a hegeliana seria, segundo esta crítica, incapaz de abarcar este outro da razão, a marca eterna da irrazão. No entanto, a verdade é que foi Hegel o grande responsável pela reviravolta da concepção de razão, que a partir dele será concebida como algo historicamente elaborado. Boa parte dos críticos ao absolutismo de Hegel permanecem inevitavelmente à mercê desta idéia hegeliana da historicidade da razão, e por mais que neguem o absolutismo do sistema hegeliano estão se movendo inteiramente dentro do terreno desvendado por Hegel. O caráter implícito desta filiação, ao invés de possibilitar um efetivo distanciamento, não faz mais do que aumentar a dependência em relação ao sistema hegeliano.

Cirne-Lima parece seguir o caminho contrário - e por isso, à primeira vista, absurdo: partindo da defesa da idéia de sistema, ele recusa a falta de radicalidade do projeto hegeliano em relação à historicidade da razão. Não se trata aqui de revelar um lado inteiramente obscuro e externo à racionalidade, a partir do qual faríamos uma defesa de algo que já seria impossível defendermos: 0 arbítrio do indivíduo. A própria razão (e o termo ganha aqui a abrangência do lógos grego, enquanto "princípio de ordem"), estruturada como sistema, encontrará dentro de si a sua insuficiência.

São três os princípios do projeto de sistema de Cirne-Lima: o princípio de identidade (incluindo a identidade simples, a iterativa e a reflexa), o princípio da diferença (diferença entre contraditórios e contrários) e o princípio da coerência ou da contradição a ser evitada. ${ }^{25}$ Se o idealismo de Cirne-Lima promove a identidade de ser e pensar que faz da razão um sistema oniabragente, por outro lado o segundo dos princípios (no que diz respeito a conceitos contrários entre si) acima apresentados revela na própria estrutura racional a insuficiência. ${ }^{26}$

por que, de Horkheimer e sobretudo Adomo, prefeririamos reter aqui, por razões que vão ser examinadas, a idéia de uma crítica interna do universo democrático, isto é, a idéia de uma crítica que, no presente, situa a utopia no seio da positividade, o não-lugar no interior do lugar, e procurar destacar as potencialidades subversivas inscritas nas promessas enunciadas, mas traídas pelo próprio universo democrático" (Heidegger e os Modernos, p. 101).

Cf. CIRNE-LIMA, Dialética e Evolução. p. 701 deste número.

Por outro lado, estranhamente a contradição por insuficiência parece não ser representada de modo pleno pelo princípio da diferença ou do acaso no projeto de sistema de Cime-Lima. O surgimento de "B" sempre ocorre tendo em vista uma estrutura de identidade previamente estabelecida de modo tautológico (o "A"): "Antes da emergência do diferente há, em princípio - por Lógica - só o idêntico, sua iteração e sua reflexão sobre si mesmo, não há, porém, a diferença" (Dialética e Evolução). Ao contrário, no sistema de Hegel o "B" é sempre inerente ao processo de desenvolvimento lógico do conceito desde 0 início, e, diante desta presença primeira, o " $\mathrm{A}$ " é resultado de uma abstração realizada a posteriori. Cabe perguntar se o "B" não exerce no projeto de Cime-Lima muito mais o papel de algo resultante de uma contradição disruptiva, do que o papel de uma antítese ínsita desde sempre no âmbito do racional, como sua insuficiência. Mas esta pergunta só pode ser colocada aqui de modo preliminar. 
É certo que o próprio Hegel já possuía no coração de seu sistema - como já afirmamos acima - a insuficiência, responsável pelo movimento dialético na superação constante dos conceitos contrários. A contradição por insuficiência ${ }^{27}$ é uma realidade no sistema de Hegel. Mas, talvez justamente devido à radicalidade das conseqüências de se colocar a insuficiência no centro da própria razão, Hegel tende a contrapor a este âmbito contingente uma síntese que termina, em alguns casos, tornando inefetiva a verdadeira antítese (e este é o caso do Weltgeist na Filosofia da História, ou da necessidade absoluta (müssen) na Ciência da Lógica). A ambigüidade com que Hegel utiliza estes e outros termos é, em determinados pontos, evidente. ${ }^{28}$ Há uma tendência a ocorrerem, nestes casos, certas aporias, seja na Fenomenologia do Espírito, na Lógica, ou na Filosofia do Direito. ${ }^{29}$

Mas, mesmo garantindo a insuficiência como presente na própria racionalidade, o sistema racional parece continuar afastando de si de modo radical todo e qualquer aparecimento de irracionalidade. Se o outro da razão está agora dentro dela, o irracional não seria uma mera fantasia especulativa? A resposta é não.

Enquanto possuindo dentro de si uma efetiva insuficiência, a razão se abre e se sujeita a possiveis manifestações do irracional (contradição disruptiva). A contradição por insuficiência é o motor a partir do qual se desenvolve o processo dialético: a contradição sintética é o movimento perpétuo de superação das insuficiências do ser. Mas, a síntese de opostos, que procura englobar o novo surgido a partir do princípio da diferença (na Lógica) e do acaso (na Natureza) - me refiro aqui ao projeto de sistema de Cirne-Lima - não se dá necessariamente (müssen), mas deve (sollen) se dar. Inevitavelmente, em alguns casos, o ser não suportará o novo que surge em si e se romperá em uma contradição disruptiva.

A partir desta concepção, não é mais possível tratar do irracional como uma alteridade absoluta que nos domina e constrange. O irracional está muito mais próximo à razão do que imaginávamos. Em alguns casos ele não será mais do que um produto de nossa própria atividade destrutiva. É muito tênue o fio que separa a razão (ou síntese de opostos) do irracional (ou ruptura de opostos) a ponto de não permitir mais ao homem uma postura arrogante e suprema frente ao mundo - algo tão comum para o homem moderno. Podemos compreender esta proximidade avaliando o modo como o lógos se instaura na atividade de qualquer ser. Imaginemos, para tanto, a maneira como a carência de alimentos atua sobre um animal, através destas quatro proposições:

1. O animal tem carência de alimentos (contradição por insuficiência);

2. A não-resolução da carência é morte (contradição disruptiva);

3. A resolução absoluta da carência também é morte (contradição disruptiva);

4. A resolução constante da carência é vida (contradição sintética).

27 Cf. LUFT, Para Uma Crítica Interna ao Sistema de Hegel, p. 83-4.

${ }_{28}$ É justamente neste ponto que surgirão as duas leituras do sistema hegeliano (como sistema aberto ou fechado) detectadas por WEBER, em Hegel. Liberdade, Estado e História.

29 Cf. as aporias (resultantes das ambigüidades) detectadas no sistema de Hegel, em LUFT, Para Uma Crítica Interna ao Sistema de Hegel, p. 60ss, 133ss e 167ss. 
A permanência do ser, seu equilíbrio vital, se dá a partir da constituição do lógos (ou unidade de opostos), na constante resolução de suas insuficiências. ${ }^{30}$ Tanto a não-resolução da contradição por insuficiência como sua resolução total fazem emergir no ser a irrazão da contradição disruptiva. Visto deste modo, fica claro que a síntese suprema (espírito absoluto na Enciclopédia de Hegel; princípio da coerência no projeto de Cirne-Lima) não possibilita jamais a eliminação da possibilidade de surgimento do irracional (contradição disruptiva), pois não elimina jamais a existência da contradição por insuficiência. O obscuro do irracional não mora na casa ao lado, ou em outra pátria, ele é o próprio lógos expatriado, o ser que, por uma razão ou outra, terminou por submergir na contradição disruptiva.

\section{Referências bỉbliográficas}

CIRNE-LIMA, Carlos Roberto V. Dialética e Evolução. Artigo presente nesta edição da Veritas. . Sobre a Contradição. Porto Alegre, Edipucrs, 1993.

FERRY, Luc e RENAUT, Alain. Heidegger e os Modernos. Trad. Alexandra Costa e Souza. Lisboa: Editorial Teorema, 1989.

HARTMANN, Nicolai. A Filosofia do Idealismo Alemão. Trad. de José Gonçalves Belo. Lisboa: Fundação Calouste Gulbenkian, 1976.

HEIDEGGER, Martin. Que é Isto - a Filosofia? Trad. de Ernildo Stein. In: Os Pensadores. São Paulo: Abril Cultural, 1979.

HEGEL, G.W.F. Enzyklopädie der philosophischen Wissenschaften. Frankfurt am Main: Suhrkamp, 1986, v. 9.

—. Phänomenologie des Geistes. Frankfurt am Main: Suhrkamp, 1986, v. 3.

- Wissenschaft der Logik. Frankfurt am Main: Suhrkamp, 1986, v. 5 e 6.

HÜHNE, Leda Miranda (org.); BORNHEIM, Gerd et al. Razões. Rio de Janeiro: Uapê, 1994.

KANT, Immanuel. Crítica da Razão Pura. Trad. de Manuela Pinto dos Santos e Alexandre Fradique Morujão. 2. ed. Lisboa: Fundação Calouste Gulbenkian, 1989.

LUFT, Eduardo. Para Uma Crítica Interna ao Sistema de Hegel. Porto Alegre: Edipucrs, 1995.

McTAGGART, J. e E. A Commentary on Hegels Logic. New York: Russell \& Russell, 1964.

MONDOLFO, Rodolfo. Heráclito. Trad. de Oberdan Galetti. 9. ed. México: Siglo XXI Editores, 1989.

MURE, G. R. G. La Filosofia de Hegel. Trad. de Alfredo Brotón Muñoz. 2. ed. Madrid: Ediciones Cátedra, 1988.

OLIVEIRA, Manfredo Araújo de. Ética e Racionalidade Moderna. São Paulo: Loyola, 1993.

SCHELLING, F. Ausgewählte Schriften. Frankfurt am Main: Suhrkamp, 1985, v. 4.

WEBER, Thadeu. Hegel. Liberdade, Estado e História. Petrópolis: Vozes, 1993.

WITTGENSTEIN, Ludwig. Tratado Lógico-Filosófico. Trad. M. S. Lourenço. Lisboa: Fundação Calouste Gulbenkian, 1987.

30 Lembremos a frase de Hegel, citada ao início deste artigo: "Só um (ser) vivo sente insuficiência; pois apenas ele é na natureza o conceito que é unidade de si mesmo e do seu contrário determinado". 